\title{
BRIEF
}

\section{Identifying Low Pharmaceutical Calculation Performers Using an Algebra-Based Pretest}

\author{
Benjamin D. Aronson, PharmD, PhD, Emily Eddy, PharmD, Brittany Long, PharmD, Olivia K. Welch, Jennifer \\ Grundey, PharmD, Jessica L. Hinson, PharmD
}

Ohio Northern University, Raabe College of Pharmacy, Ada, Ohio

Corresponding Author: Emily Eddy, Ohio Northern University, Raabe College of Pharmacy, 525 S Main St, Ada, OH 45810. Tel: 419-772-2305. Email: e-eddy.1@onu.edu

Submitted November 12, 2020; accepted May 7, 2021; ePublished May 2021

\begin{abstract}
Objective. To determine if a pretest assessing algebra-based problem-solving skills could aid in identifying those who may underperform in calculations course assessments and if this provides additional value beyond pre-admission and demographic characteristics.

Methods. Student pharmacists were screened for algebraic problem-solving skills using an 18-item pretest taken the semester prior to a course containing pharmaceutical calculations content. These scores were compared to later performance on pharmaceutical calculations assessments. Linear regression models were computed to determine the relationship between pretest scores and pharmaceutical calculations performance, after controlling for pre-admission factors and demographic characteristics.

Results. The median pretest score was 15 out of 18 possible points, with scores ranging from 5 to 18 correct. After controlling for age, gender, ACT scores, and high-school GPA, scores on the algebra-based, word-problem pretest were associated with performance on pharmaceutical calculation assessments.

Conclusion. This research demonstrates the ability of a pretest, aimed at identifying deficiencies in algebraic problemsolving skills, to identify those at risk of failing to obtain mastery of pharmaceutical calculations, even after controlling for demographics, prior grades, and prior standardized test scores. Identifying these students is a first step towards implementing tailored interventions to improve students' algebra-based word problem skills in order to prevent deficiencies in pharmaceutical calculations mastery before class even begins.

Keywords: pharmaceutical calculations, calculations, academic performance
\end{abstract}

\section{INTRODUCTION}

Mastery of pharmaceutical calculations is of vital importance for student pharmacists given the ramifications of errors and mistakes in pharmacy practice. We observed a greater number of students each year with deficient grades in introductory pharmaceutical calculations (henceforth, calculations) content at our institution. This trend, while only recently observed locally, may not be so recent. Latif and Grillo (2002) reported a large proportion of students entering pharmacy school 20 years ago who "may be deficient in basic math skills."

There are a variety of course designs ${ }^{2-5}$ and assessment models ${ }^{5,6}$ for calculations. We first attempted to improve student performance and reverse the trend by using evidence-based educational practices such as incorporating a flipped classroom approach ${ }^{7}$ and repeated testing of calculations, ${ }^{8}$ but saw no appreciable impact. The teaching team probed our experiences to identify the underlying problem; we hypothesized that some students may lack basic problem-solving and algebraic skills and could benefit from some form of basic skills development prior to our course. But first, those students had to be identified. The ability to identify students who may struggle with calculations would assist educators in providing tailored and targeted support, and interventions to improve ability.

Previous literature has detailed several demographic and pre-admission characteristics that may impact mastery of calculations content. Pre-admission variables such as overall Pharmacy College Admission Test (PCAT) scores, PCAT quantitative ability scores, and undergraduate math/science grade point average (GPA) have been identified..$^{9-14}$ In addition, performance in similar past courses are good predictors of performance, and time away from material can be detrimental to performance. ${ }^{10}$

Instead of using administrative pre-admission data, what if an algebra-based pretest could be given to identify those at risk? Indeed, such a test, the Basic Math Skills Test (BMST) was reported in the literature nearly 2 decades ago. The BMST was a 50-item test measuring math ability at the eighth grade level. BMST scores among student pharmacists correlated well with preadmission markers linked to calculations performance, ${ }^{1,9,11}$ and improved the variance explained by a linear regression model for calculations course scores beyond those markers. ${ }^{9}$ The BMST, while promising, was not 
considered for the present research as there is limited current information regarding this test. Instead, the notion of identifying those at risk of deficiencies, going beyond demographic and pre-admission characteristics, was put into use in this research.

The purpose of this study was to determine if a pretest assessing algebra-based problem-solving skills could aid in identifying those who may underperform in calculations course assessments and if this provides additional value beyond pre-admission and demographic characteristics.

\section{METHODS}

This IRB exempt observational study investigated calculations performance in a cohort of student pharmacists at a 0-6, direct-entry PharmD program. The Profession of Pharmacy (PoP 1-5) sequence at Ohio Northern University consists of 5 sequential 2-credit, semester long courses containing a variety of pharmacy related content; professionalism, pharmaceutical care, the Pharmacist's Patient Care Process, introduction to the U.S. health care system, drug information and calculations. The calculations content is divided between 2 courses, with half taught and assessed in PoP 3 during students' 3rd semester of the program, and the remainder taught in PoP 5. Topics taught and assessed in PoP 3 include aliquots, dosing, expressions of concentration, dilution/concentration, reconstitutions, prefabricated dosage forms, units of potency, and alligation. This is a didactic course with mastery of the content assessed through 3 summative exams during PoP 3, and a subsequent review exam during PoP 4 (a course containing no new calculations content).

The sample consisted of students who entered the pharmacy program in the fall of 2017, took PoP 3 in the fall of $2018(\mathrm{n}=118 / 123 ; 96 \%)$, and who consented to participate in this research during a math pretest administered during PoP 2

Students took an 18-item math pretest (available upon request) in the spring semester of their first year in the program during PoP 2. This pretest contains 17 free response word problems and 1 multiple choice question. The pretest was developed to evaluate algebraic problem-solving and application of proportional reasoning, unit analysis, and percentages using both pharmacy and non-pharmacy related concepts. For instance, one item assessing proportional reasoning indicated a set number of children per adult attending a movie, gave the total attendees, and asked for the number of children in attendance. The pretest was administered to students electronically over twenty minutes using the learning management system. Students were allowed to use a calculator. No partial credit was awarded for incorrect answers.

Calculations performance was assessed in two ways. Individual student scores from 3 summative 50-point calculations exams administered during PoP 3 were obtained from course instructors. These exams vary in number of questions and are not inherently cumulative, but may require integration of concepts previously tested. Similar to the pretest, questions on the exams were open-ended word problems. Scores from these three assessments were summed. Student scores from a 12-item 60 point cumulative calculations review examination administered in PoP 4 were also obtained from course instructors. Here again, answers were scored as correct or incorrect with no partial credit given.

Demographic and pre-admission characteristics were collected from administrative records for all study participants. These included gender, age, ACT total, ACT subscores (ie, math, science, English), and high school GPA.

All statistics were computed using the Statistical Package for Social Science (SPSS, Version 25). Descriptive statistics were used to characterize the samples and inspect the variables. Pearson correlation coefficients were computed between pretest scores, demographic characteristics, and pre-admission factors, and calculations performance. Linear regression models were used to understand the relationship between pretest scores and calculations performance after controlling for demographic and pre-admission factors. For correlational and regression analyses, listwise deletion of those cases with missing values was used, resulting in an overall analytic sample of 105 students.

\section{RESULTS}

The mean age of consenting participants was 20 years during PoP 3, and female was the gender listed for $63 \%$ of students. The median composite ACT score was 26, with math, science, and English sub-score medians of 27, 27, and 25, respectively. The mean adjusted high school GPA for this group was 3.99. Of note, adjusted GPAs may be above 4.0 due to weighting of advanced courses. Descriptive statistics of the pretest and calculations assessments is shown in Table 1.

Bivariate correlations between all study variables are shown in Table 1. Pretest scores and pre-admission factors were positively and significantly associated with calculations performance.

The results from ordinary least squares regression models for the total points earned on the PoP 3 calculations exams and for the PoP 4 cumulative review exam are displayed in Table 2. The pretest was associated with both indicators of calculations performance, net the effect of ACT sub-scores, high school GPA, age, and gender.

\section{DISCUSSION}


Research in the early 2000s sought to identify potential low calculations performers by administering a mathematics exam. ${ }^{1,9,11}$ This present work sought to continue and reignite that inquiry to help identify students who face difficulty in mastering calculations content. We found that performance on a pretest aimed at identifying deficiencies in algebraic problem-solving skills was related to calculations scores within a calculations course, and also scores on a review exam a semester later. Most notably, this relationship persisted after controlling for age, gender, earlier grades, and ACT subscores. This may imply there is merit to more deeply understanding the underlying skills that students lack and attempting to support students in these areas.

Here we found that an algebra-based pretest was an indicator of future calculations success, but it is also possible that this test could be applied to other courses with similar skill sets. For instance, to identify students at-risk of having difficulty with pharmacokinetics content, calculations and pharmacokinetic content on the PCOA, calculations content on the NAPLEX, and most importantly, performance in the real world when it really counts for patient safety and outcomes. Future research can explore these relationships, as well as the impact of interventions at mitigating the impact of preexisting deficiencies in student skills.

The present findings must be juxtaposed with limitations. First and foremost, the study was conducted at a single, private 0-6 direct-entry pharmacy program. This may limit generalizability to other PharmD programs. For instance, calculations performance in the present study represents only half of the traditional calculations content due to the organization of our curriculum. And while the present study found similar factors were associated with calculations ability at our program compared to prior research in $2+4$ PharmD programs (ie, prior grades and standardized test scores), ${ }^{9-15}$ there are possible differences that warrant caution when applying these findings en masse. For instance, students entering a 4-year PharmD program would likely have a stronger pre-graduate didactic base, including possible undergraduate coursework in mathematics, which may have bearing on performance. ${ }^{10}$

The pretest used in this study was not fully validated or subjected to advanced psychometric testing. It is noteworthy that a rather simple and brief test was so strongly related to calculations performance, even after adjusting for standardized test scores and GPA. This suggests that other programs could institute their own tests developed to identify deficiencies in students, with the goal of program creation or resource allocation to help students achieve academic success. As we consider our pretest, it aided in identifying students at risk of failure, but did not diagnose the root of the problem. After establishing the link between pretest and calculations performance, our institution used the pretest more broadly for two years; as a self-assessment for students to identify their own learning needs while subsequently offering a mathematics mindset and problem-solving workshop series aimed at building student ability. This raises an additional limitation of the present work. Even with a variety of potential indicators, the models in this study explain only $30 \%$ of the variability in calculations performance. There are a variety of additional factors beyond and outside of the pretest and pre-admission characteristics that influence calculations performance. Student study habits ${ }^{15}$, mathematical identity, ${ }^{16-17}$, mindset, ${ }^{18-19}$ motivation, ${ }^{20}$ social support ${ }^{21}$ accountability, ${ }^{22}$ critical thinking, ${ }^{23}$ and metacognitive ability ${ }^{24}$ are just a few of the possible areas to assess and create interventions that may impact calculations performance.

As an academy, the work of designing methods to identify students who require additional support to develop into excellent pharmacists is needed. One possible method would be to assign online modules of content for those students to complete during the semester, which has been reported as successful in remediating deficiencies in broader content like prior biochemistry, mathematics and chemistry experience. ${ }^{25-26}$ Students could be given those modules along with pharmaceutical calculations content to better support them for success. Students could also be paired with mentors that could work with them in remediating algebra-based skills as well as supporting them through pharmaceutical calculations. ${ }^{9}$

Future work could further expand on the pretest to target specific skills. This will allow us to hone in on specific interventions for specific students such as algebra review, problem-solving skills, growth mindset, or other interventions. It is important to identify those who will struggle with pharmaceutical calculations, and determine how to intervene and provide support.

\section{CONCLUSION}

This work demonstrates that scores on a pretest aimed at identifying deficiencies in algebraic problem-solving skills are associated with calculations performance, even after controlling for age, gender, earlier grades, and standardized test scores. This study identifies the demographic and pre-admission characteristics associated with low performance in calculations and provides proof of concept supporting development of a validated tool to identify possible low performers. Colleges of pharmacy have a vested interest in ensuring student mastery in calculations and can use a similar tool to identify those needing extra support in the PharmD curriculum. Once those at risk have been identified, educational interventions can then be designed to support those students. 


\section{REFERENCES}

1. Latif DA, Grillo JA. Assessing the basic math skills of first-year doctor of pharmacy students. J Pharm Teach. 2003;9(2):17-25.

2. Davies M, Pon D, Garavalia LS. Improving pharmacy calculations using an instructional design model. Am J Pharm Educ. 2018;82(2):6200. doi:doi.org/10.5688/ajpe6200

3. Delafuente JC, Araujo OE, Legg SM. Traditional lecture format compared to computer-assisted instruction in pharmacy calculations. Am J Pharm Edu. 1998;62:62-66.

4. Lacroix M, McCall KL III, Fike DS. The Keller personalized system of instruction in a pharmacy calculations course: A randomized trial. Curr Pharm Teach Learn. 2014;6(3):348-352.doi:doi.org/10.1016/j.cptl.2014.02.002

5. Brown MC, Hanggi A. Pharmaceutical calculations instruction and assessment in US colleges and schools of pharmacy. Am J Pharm Educ. 2007;71(5):87. doi: 10.5688/aj710587

6. Sheaffer EA, Addo RT. Pharmacy student performance on constructed-response versus selected-response calculations questions. Am J Pharm Educ. 2013;77(1):6. doi:doi.org/10.5688/ajpe7716

7. Cotta KI, Shah S, Almgren MM, Macías-Moriarity LZ, Mody V. Effectiveness of flipped classroom instructional model in teaching pharmaceutical calculations. Curr Pharm Teach Learn. 2016;8(5):646653.doi:10.1016/j.cptl.2016.06.011

8. Coker AO, Lusk KA, Maize DF, et al. The effect of repeated testing of pharmacy calculations and drug knowledge to improve knowledge retention in pharmacy students. Curr Pharm Teach Learn. 2018;10(12):16091615. doi:10.1016/j.cptl.2018.08.019

9. Latif DA. The relationship among pharmacy students basic math scores, traditional preadmission indicators and performance in pharmaceutical calculations course. J Pharm Teach. 2002;10(1):17-29.

10. Conn KM, Birnie C, McCaffrey D, Brown J. The relationship between prior experiences in mathematics and pharmacy school success. Am J Pharm Educ. 2018;82(4):6257. doi:10.5688/ajpe6257

11. Grillo JA, Latif DA, Stolte SK. The relationship between preadmission indicators and basic math skills at a new school of pharmacy. Ann Pharmacother. 2001;35(2):167-172.

12. Dell KA, Wantuch GA. Predicting success in pharmaceutical calculations. Curr Pharm Teach Learn. 2019;11(10):972-978. doi: 10.1016/j.cptl.2019.06.002

13. Shara M, Augustine SC, Siracuse MV. Predictors of success in pharmacy calculations: comparison of students enrolled in campus and distance pathways [abstract]. In: 109th Meeting of the American Association of Colleges of Pharmacy; 2008 July 19-23; Chicago, IL.

14. Greenwood R, Al-Achi A, D'Elia R, Junker J, Swanson L, Teat D. Academic factors affecting success in various courses in the pharmacy curricula [abstract]. Am J Pharm Educ. 2002;66(Winter Supplement):105S.

15. Boudinot SG, Martin B. Factors influencing pharmaceutical calculations grades: is more study time better? [abstract]. Am J Pharm Educ.1997;61(Winter Supplement):97S.

16. Allen K, Schnell K. Developing Mathematics Identity. Mathematics Teaching in the Middle School. 2016;21(7): 398-405. doi:10.5951/mathteacmiddscho.21.7.0398

17. Heffernan K, Peterson S, Kaplan A, Newton KJ. Intervening in student identity in mathematics education: an attempt to increase motivation to learn mathematics. Int Elect J Math Ed. 2020;15(3):em0597. doi: 10.29333/iejme/8326

18. Calo M, Peiris C, Chipchase L, Blackstock F, Judd B. Grit, resilience and mindset in health students. Clin Teach. 2019;16(4):317-322. doi: 10.1111/tct.13056

19. Cooley JH, Larson S. Promoting a growth mindset in pharmacy educators and students. Curr Pharm Teach Learn. 2018;10(6):675-679. doi: 10.1016/j.cptl.2018.03.021

20. Edgar S, Carr SE, Connaughton J, Celenza A. Student motivation to learn: is self-belief the key to transition and first year performance in an undergraduate health professions program? BMC Med Educ. 2019;19(1):111. doi: 10.1186/s12909-019-1539-5

21. Park KH, Kim D-H, Kim SK, et al. The relationships between empathy, stress and social support among medical students. Int J Med Educ. 2015;6:103-108. doi: 10.5116/ijme.55e6.0d44

22. Perry C, Henderson A, Grealish L. The behaviours of nurses that increase student accountability for learning in clinical practice: An integrative review. Nurse Educ Today. 2018;65:177-186. doi:10.1016/j.nedt.2018.02.029

23. Persky AM, Medina MS, Castleberry AN. Developing critical thinking skills in pharmacy students. Am J Pharm Educ. 2019;83(2):7033. doi: doi.org/10.5688/ajpe7033

24. Medina MS, Castleberry AN, Persky AM. Strategies for improving learner metacognition in health professional education. Am J Pharm Educ. 2017;81(4):78. doi: 10.5688/ajpe81478 
25. Verdone M, Joshi MD, Bodenstine TM, et al. An online, self-directed pharmacy bridging course for incoming first-year students. Am J Pharm Educ. 2020;84(7):ajpe7684. doi:doi.org/10.5688/ajpe7684

26. McLaughlin JE, Khanova J, Persky A, Hathaway N, Cox W. Design, implementation, and outcomes of a threeweek pharmacy bridging course. Am J Pharm Educ. 2017;81(7):6313. doi:10.5688/ajpe8176313 
Table 1. Descriptive statistics of pretest and calculations performance

\begin{tabular}{llccc}
\hline Variables & $\begin{array}{l}\text { Possible } \\
\text { range }\end{array}$ & $\begin{array}{c}\text { Minimum score } \\
(\boldsymbol{\%})\end{array}$ & Median score (\%) & $\begin{array}{c}\text { Maximum score } \\
(\boldsymbol{\%})\end{array}$ \\
\hline Pretest & $0-18$ & $5(28 \%)$ & $15(83 \%)$ & $18(100 \%)$ \\
PoP 3 exam 1 & $0-50$ & $9.5(19 \%)$ & $39.5(79 \%)$ & $50(100 \%)$ \\
PoP 3 exam 2 & $0-50$ & $6(12 \%)$ & $42(84 \%)$ & $50(100 \%)$ \\
PoP 3 exam 3 & $0-50$ & $0(0 \%)$ & $41(82 \%)$ & $50(100 \%)$ \\
PoP 3 exam sum & $0-150$ & $32.5(81 \%)$ & $122(81 \%)$ & $150(100 \%)$ \\
PoP 4 review exam & $0-60$ & $35(58 \%)$ & $55(92 \%)$ & $60(100 \%)$ \\
\hline
\end{tabular}

PoP 3 Profession of Pharmacy 3, contains $1 / 2$ pharmaceutical calculations materials;

PoP 4 Profession of Pharmacy 4, non-pharmaceutical calculations course

Table 2. Bivariate Pearson correlations among study variables $(n=105)$

\begin{tabular}{|c|c|c|c|c|c|c|c|c|c|}
\hline & 1. & 2. & 3. & 4. & 5. & 6. & 7. & 8. & 9. \\
\hline 1. Age & 1 & & & & & & & & \\
\hline 2. Gender & -.07 & 1 & & & & & & & \\
\hline 3. ACT math sub-score & -.05 & -.08 & 1 & & & & & & \\
\hline 4. ACT science sub-score & -.11 & -.11 & $.68^{\mathrm{a}}$ & 1 & & & & & \\
\hline 5. ACT English sub-score & -.05 & .14 & $.51^{\mathrm{a}}$ & $.57^{\mathrm{a}}$ & 1 & & & & \\
\hline 6. High school GPA & .02 & .17 & $.31^{\mathrm{a}}$ & $.30^{\mathrm{a}}$ & $.39^{\mathrm{a}}$ & 1 & & & \\
\hline 7. Pretest & -.01 & -.01 & $.39^{\mathrm{a}}$ & $.28^{\mathrm{a}}$ & $.25^{\mathrm{a}}$ & .13 & 1 & & \\
\hline 8. Calculations exam sum & .01 & -.03 & $.52^{\mathrm{a}}$ & $.42^{\mathrm{a}}$ & $.39^{\mathrm{a}}$ & $.21^{\mathrm{a}}$ & $.41^{\mathrm{a}}$ & 1 & \\
\hline 9. Cumulative review exam ${ }^{\mathrm{b}}$ & .20 & -.12 & $.45^{\mathrm{a}}$ & $.36^{\mathrm{a}}$ & $.43^{\mathrm{a}}$ & $.21^{\mathrm{a}}$ & $.39^{\mathrm{a}}$ & $.49^{\mathrm{a}}$ & 1 \\
\hline
\end{tabular}

${ }^{\mathrm{a}} p<.05$; $\mathrm{b}$ list-wise deletion for these comparisons resulted in $\mathrm{n}=96$ 
Table 3. Ordinary least squares regression model for calculations performance

\begin{tabular}{lllll}
\hline & \multicolumn{2}{c}{ Sum of calculations exams } & \multicolumn{2}{c}{ Cumulative review exam } \\
Independent variable & $\begin{array}{l}\text { Standardized } \\
\text { beta }\end{array}$ & $\boldsymbol{p}$-value & $\begin{array}{l}\text { Standardized } \\
\text { beta }\end{array}$ & $\boldsymbol{p}$-value \\
\hline Age & 0.04 & 0.65 & $\mathbf{0 . 1 9}$ & $\mathbf{0 . 0 4}$ \\
Gender & -0.01 & 0.90 & -0.10 & 0.29 \\
ACT math sub-score & $\mathbf{0 . 3 0}$ & $\mathbf{0 . 0 1}$ & 0.20 & 0.10 \\
ACT science sub-score & 0.07 & 0.56 & 0.00 & 0.98 \\
ACT English sub-score & 0.14 & 0.22 & $\mathbf{0 . 2 8}$ & $\mathbf{0 . 0 2}$ \\
High school GPA & 0.02 & 0.86 & -0.01 & 0.92 \\
Pretest & $\mathbf{0 . 2 4}$ & $\mathbf{0 . 0 1}$ & $\mathbf{0 . 2 4}$ & $\mathbf{0 . 0 1}$ \\
Model adjusted $\mathrm{R}^{2}$ & & 0.295 & & 0.298 \\
\hline
\end{tabular}

